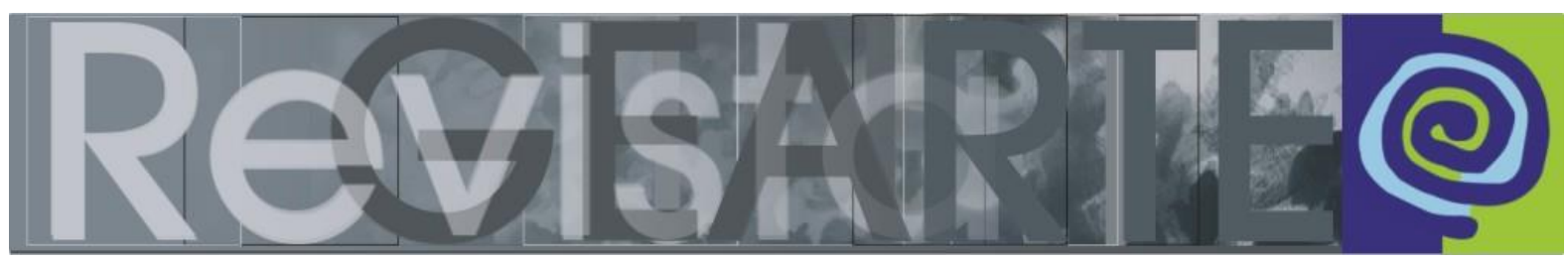

e-ISSN 2357-9854

\title{
Artes visuais e tecnologias na educação: história e contemporaneidade
}

Vivemos atualmente o que poderíamos chamar de era das interfaces, estamos em constate interação com as tecnologias, sobretudo, com as tecnologias de comunicação em rede - computadores, tabletes e os, onipresentes, celulares. O ambiente virtual tornou-se o território privilegiado e norteador de trocas - simbólicas, artísticas, culturais, sociais, econômicas, políticas e afetivas. $O$ advento da Web 2.0 permitiu aos consumidores de conteúdo tornarem-se também produtores - dando origem a prossumidores. O recente Projeto Alfabetismo Transmedia: un programa de investigación (2017), liderado pelo pesquisador Carlos Scolari, buscou ampliar e entender pesquisa realizada por Henry Jenkins, que havia identificado nove zonas de ação dos jovens estadunidenses vinculadas aos videojogos e à internet (produção; narrativa e estética; gestão social; gestão individual; gestão de conteúdos; mídias e tecnologias; ideologia e ética; prevenção de riscos; e performance). Nesse sentido, o Projeto liderado por Scolari identificou quarenta e quatro competências com destaque à "produção de conteúdos", como área de maior atuação dos adolescentes. Tal estudo alerta para a importância de repensarmos continuamente as relações, cada vez mais intensas, entre os processos de produção de conteúdo, aprendizagem e utilização das tecnologias e das mídias em rede. No entanto, se os entrecruzamentos entre arte, educação e tecnologias midiáticas em rede se multiplicam, nem sempre eles são efetivos.

Tendo em mente essa realidade, propusemos esse dossiê como espaço para a discussão e a reflexão acerca de como os processos artísticos e educativos, bem como a própria ideia de arte educação são atravessados pelas novas dinâmicas estabelecidas pelos ambientes digitais. Convidamos assim à reflexão sobre diferentes perspectivas de abordagem dos recentes debates sobre as apropriações e os usos socioculturais na "vida nas plataformas" (FERNÁNDEZ, 2018). Entre outros temas, nos referimos às formas como se estabelecem os intercâmbios e experiências educacionais: os fluxos ascendentes ou descendente de produção de conteúdo, sua direcionalidade, os processos de circulação de conteúdos, suas características estilísticas e enunciativas, em reflexões sobre experiências que envolvam arte, educação e tecnologias, em suas múltiplas possibilidades combinatórias. 


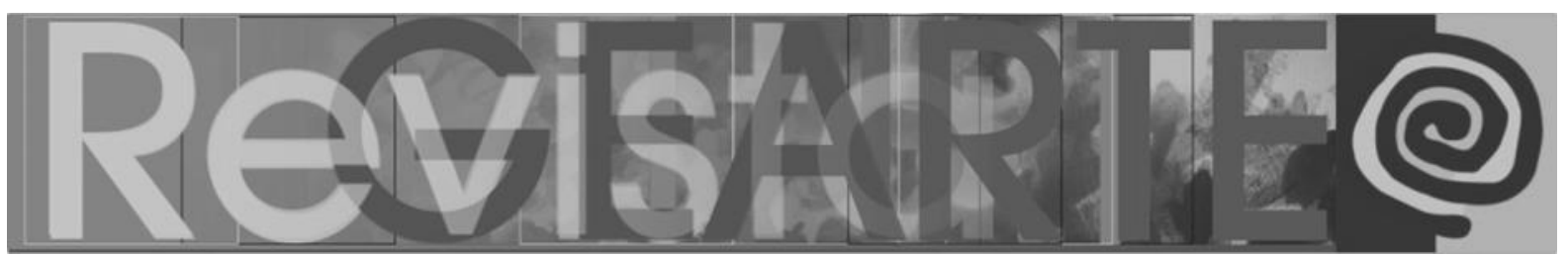

Abrimos esse dossiê com o artigo "La búsqueda del perfil docente en educación artística a través del mPortafolio", de Noemi Peña Sanchez, professora e pesquisadora da Universidad de La Laguna (Espanha) que propõe uma reflexão sobre as vantagens do portfólio de aprendizagem por meio do uso de aplicativos móveis educacionais, o mPortafolio, que ao mesmo tempo em que aproveitam a inevitável presença de dispositivos móveis em sala de aula, ressignificam essas tecnologias digitais para dotá-las de valor educacional no treinamento em Educação Artística. O estudo aborda dois tópicos de interesse: o papel do portfólio de aprendizagem como recurso para a reflexão individual e colaborativa da aprendizagem dentro e fora da sala de aula de Educação Artística; a pesquisa da prática docente mostra as possibilidades oferecidas pelos dispositivos móveis testando formas participativas de aprendizagem que transformam a sala de aula em um espaço híbrido entre o rosto, o digital e o interativo.

No artigo "Imaginário, subjetividade e tecnologia na formação docente em artes visuais", os autores Cláudia Mariza Mattos Brandão e Cláudio Tarouco de Azevedo, ambos professores da Universidade Federal de Pelotas (Pelotas/RS, Brasil), refletem sobre a influência e o impacto do desenvolvimento tecnológico sobre as pessoas do século XXI, que atestam a importância de discussões versando sobre o assunto no âmbito da educação. Amparado principalmente em Gilbert Durand e Félix Guattari, o artigo problematiza as mudanças operadas na ordem visual, processadas nos jogos técnicos que originam as imagens, suas reverberações nas subjetividades e os processos educativos, colocando em jogo os mecanismos perceptivos e o envolvimento dos espectadores no campo de intercâmbio constituído pelas imagens. Sendo assim, o texto visa refletir sobre o impacto da tecnologia sobre a vida em sociedade e o papel fundamental da educação, não somente como possibilidade de capacitação a práticas técnicas, mas, principalmente, como utilização dos novos meios em atividades expressivas e reflexivas, de produção de subjetividade, abordando práticas pedagógicas vinculadas à formação docente em Artes Visuais e seus resultados.

"Cérebros criativos no mundo das produções audiovisuais de massa? Entretenimento, fãs de animações e possibilidades criativas em artes visuais", de Isac dos Santos Pereira, da Universidade Anhembi Morumbi (São Paulo/SP, Brasil), surgiu da inquietação suscitada no autor a partir da reflexão sobre até que ponto a comunicação audiovisual, especificamente as VAZQUEZ, Cecilia; MEDEIROS, Rosângela Fachel de; POZZI, Marion Divério Faria; SOUZA, Adrise Ferreira de. 6 Artes visuais e tecnologias na educação: história e contemporaneidade.

Revista GEARTE, Porto Alegre, v. 6, n. 1, p. 5-9, jan./abr. 2019.

Disponível em: http://seer.ufrgs.br/gearte 


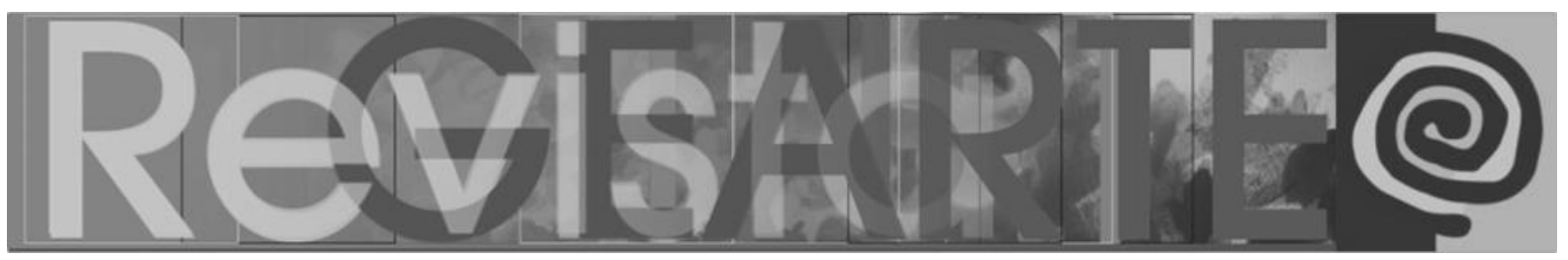

animações televisivas, e seus hiperestímulos deixam de ser mero entretenimento dentro do complexo contemporâneo para de fato serem úteis para os estudos da criatividade, além de subsidiar no processo criativo de seus fãs. A assimilação de tais constructos carece da atuação de diversos campos sensoriais, que retém e encaminham as informações às diversas vias cerebrais. Em diálogo com o pensamento complexo de Edgard Morin, o texto se funda na intenção de entender algumas das faces das animações infanto-juvenis enquanto arcabouço complexo, que se instaura e afeta diversos campos do imaginário e, tão logo propicia o ato criador ao propor novas animações, como o caso de alguns produtores. Doravante, os olhares investigativos lançaram-se aos escritos partindo de uma concepção positiva sobre os meios audiovisuais, visando discutir sobre algumas produções e, sua consequente influência na conformação do arcabouço imagético das crianças/ã̃s que as consomem constantemente nos momentos de lazer, os agregam e externalizam suas percepções por meio de desenhos dentro da sala de aula.

E "Emoticons e Letramento Visual Pedagogia da Imagem", de Ana Valéria de Figueiredo da Costa e Isabel Almeida Carneiro, da Universidade do Estado do Rio de Janeiro (Rio de Janeiro/RJ, Brasil), nos propõe uma imersão consciente no universo dos emoticons. "Você está em silêncio e, de repente, seu telefone celular emite um som avisando que chegou mensagem pelo aplicativo whattsApp, popularmente conhecido com zap. Por um momento, a atividade que se realiza é interrompida. Não se lê nenhuma palavra escrita; aparece apenas figurinha (conhecida como emoji, emoticon ou smile) avisando que a resposta que se esperava é positiva. Sem nenhuma palavra escrita ou gravada, você - e eu também - entendemos que tudo está bem resolvido". A partir dessa contextualização, tomando por base a força da imagem como comunicação e, ainda, a facilidade de acesso às novas Tecnologias Digitais de Informação e Comunicação (TDIC) nos dispositivos móveis, o artigo tem como objetivo propor reflexões sobre a utilização de imagens para a comunicação sem palavras, porém repleta de significados partilhados.

Já "O patrimônio artístico e cultural do estado do Espírito Santo a reformulação do ensino da arte a partir da Base Nacional Comum Curricular e o uso da tecnologia na prática educativa", de Cláudia Botelho, da Secretaria Estadual de Educação do Espírito Santo (Vitória/ES, Brasil) apresenta uma análise da reelaboração do currículo do estado do Espírito Santo- Educação VAZQUEZ, Cecilia; MEDEIROS, Rosângela Fachel de; POZZI, Marion Divério Faria; SOUZA, Adrise Ferreira de. Artes visuais e tecnologias na educação: história e contemporaneidade.

Revista GEARTE, Porto Alegre, v. 6, n. 1, p. 5-9, jan./abr. 2019.

Disponível em: http://seer.ufrgs.br/gearte 


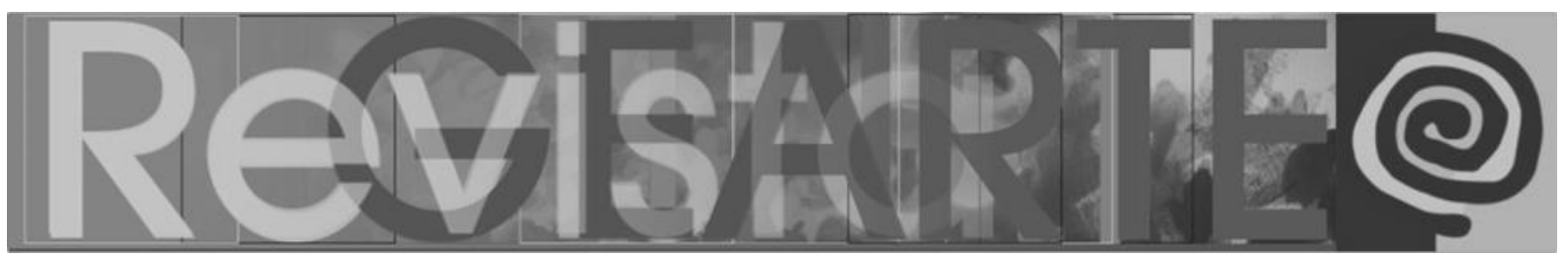

Infantil e Ensino Fundamental, no componente curricular Arte, sua interação com a educação multicultural e com o uso da tecnologia no ensino. A revisão do currículo de Arte pela abrangência da Base Nacional Comum Curricular desperta para uma educação que dialogue com as diversidades locais em interação com diferentes culturas nacionais e internacionais. Nesse processo a tecnologia se torna uma ferramenta e uma linguagem de aproximação da cultura diversa entre estudantes de diferentes partes do estado, além de proporcionar a apreciação estética e a interação virtual com obras de artes e de manifestações da cultura popular do estado do Espírito Santo.

O artigo "Jogos Digitais e arte-educação: acepções gerais", de Sara Raquel Andrade Silva, da Universidade Federal Rural do Rio de Janeiro (Seropédica/RJ, Brasil), tem a intenção de apresentar, de forma breve, as possibilidades pedagógicas na utilização dos jogos digitais como ferramenta no ensino de arte. Relacionando o contexto atual dos videogames, isso é, a discussão sobre seu caráter artístico como analogia para facilitar a assimilação dos movimentos artísticos nos mais variados contextos históricos. $\mathrm{O}$ trabalho ainda faz apontamentos acerca do impacto da tecnologia na aprendizagem de jovens e crianças e a maneira como o uso do videogame apresenta soluções para novas demandas pedagógicas.

Encerramos o dossiê com o ensaio visual Proposições artísticas e jogos similares, Rafael Schultz Myczkowski, da Universidade do Estado de Santa Catarina (Florianópolis/SC, Brasil), fruto de atividade desenvolvida aa disciplina "Sobre Ser Artista Professor", ministrada pela Professora Dra. Jociele Lampert no Programa de Pós-Graduação em Artes Visuais da Universidade do Estado de Santa Catarina - UDESC/CEART.

Gostaríamos de agradecer aos autores dos textos que compõe este dossiê e a Umbelina Barreto pela criação da capa.

Desejamos a todos e todas uma ótima leitura! 


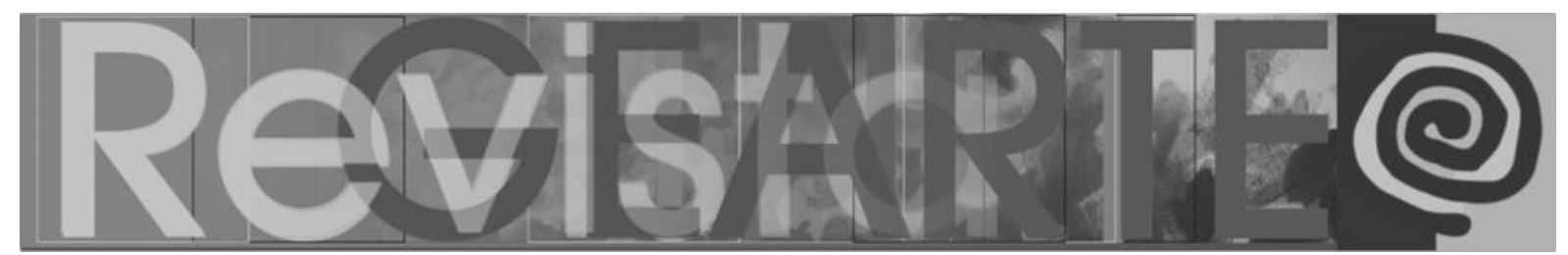

Dra. Cecilia Vazquez ${ }^{1}$

(Universidade de Buenos Aires - UNGS, Buenos Aires, Argentina)

Dra. Rosângela Fachel de Medeiros ${ }^{2}$

(Universidade Federal de Pelotas - UFPEL, Pelotas/RS, Brasil)

Dra. Marion Pozzi ${ }^{3}$

(Universidade Federal do Rio Grande do Sul - UFRGS, Porto Alegre/RS, Brasil)

Dnda. Adrise Ferreira de Souza ${ }^{4}$

(Universidade Federal do Rio Grande do Sul - UFRGS, Porto Alegre/RS, Brasil)

Organizadoras do presente número

\section{Referência}

FERNÁNDEZMASALA, María Belen. Las mediaciones tecnológicas: tramas estructural-simbólicas del orden ins tucional. In: LAGO MARTíNEZ, Silvia et al. (Orgs.). Acerca de la apropiación de tecnologías Teoría, estudios y debates- 1a ed. Rada Tilly: Del Gato Gris; Ciudad Autónoma de Buenos Aires: IIGG - Instituto de Investigaciones Gino Germani; Ciudad Autónoma de Buenos Aires: Red de Investigadores sobre Apropiación de Tecnologías, 2018. p. 153-166.

1 Es Licenciada em Ciencias de la Educación. Cursó la Maestría en Tecnología Educativa (Universidad de Buenos Aires -UBA). Se especializa en tecnología educativa integrando equipos de trabajo que desarrollan proyectos de innovación en temas de inclusión de tecnologías en educación. Se desempeñó como coordinadora en el área pedagógica de la UNTREF Virtual, actualmente integra el equipo de educación de Chequeado y Chicas en Tecnología. Asimismo realiza asesoría en proyectos sobre virtualización de contenidos. Es docente virtual en cursos de formación docente. Participa en diferentes investigaciones relacionadas al tema de educación y tecnologías. Integra el equipo de trabajo del Diploma en Currículum y Prácticas Escolares en Contexto (FLACSO). E-mail: ceci_vaz@hotmail.com

2 Doutora e mestre em Literatura Comparada pela Universidade Federal do Rio Grande do Sul (UFRGS/CAPES). Professora do Curso de Letras e do Mestrado em Letras da Universidade Regional Integrada do Alto Uruguai e das Missões (UR/FW). Atualmente, é professora visitante do Mestrado em Artes Visuais da Universidade Federal de Pelotas. É colíder do Grupo de Pesquisa "Narrativas Contemporâneas e Estudos Culturais" (CNPq/URIFW), e participa também dos GPs "Cinema Latino-Americano" (CNPq/UFF) e "Cinema da América Latina e Vanguardas Artísticas GECILAVA- (CNPqUNIFESP). Integra a Red lberoamericana de Investigación en Narrativas Audiovisuales RedINAV, e a Red de Investigadores sobre Cinema Latinoamericano - RICiLa. Atua em comitês editorias de revistas nacionais e internacionais e é Editora da Revista Língua \& Literatura. Atualmente, sua principal área de interesse são as narrativas audiovisuais latino-americanas contemporâneas, temática que norteia seus projetos de ensino, pesquisas e extensão. Email: rosangelafachel@gmail.com

3 Professora Adjunto da Faculdade de Arquitetura da Universidade Federal do Rio Grande do Sul (UFRGS), lotada no Departamento de Design e Expressão Gráfica. Doutora pelo Programa de Pós-Graduação em Educação PGEDU/UFRGS. Mestre pelo Programa de Pós-Graduação em Arquitetura PROPAR/UFRGS. Graduada em Arquitetura e Urbanismo pela Faculdade de Arquitetura FAUJFRS. Experiência em pesquisa no campo da Semiótica Discursiva/ Semiótica Visual com ênfase em linguagens sincréticas e na Habitabilidade das edificações com ênfase em iluminação natural. Experiência em extensão na abordagem do Design Social. Experiência acadêmica nas áreas de Arquitetura, Engenharias, Design Visual e Design de Produto com ênfase em linguagens sincréticas e linguagens gráficas. Pesquisadora do Grupo de Pesquisa em Educação e Arte GEARTE/UFRGS. Email: marionpozzi@gmail.com

4 Doutoranda em Educação pela Universidade Federal do Rio Grande do Sul - PPGEDU/UFRGS. Mestra em Artes Visuais pela Universidade Federal de Pelotas - UFPEL. Graduada em Artes Visuais Licenciatura pela Universidade Federal do Rio Grande-FURG. Professora Substituta de fotografia no curso de Design da UFPEL. Integrante do Grupo de Pesquisa em Educação e Arte (GEARTE/UFRGS/CNPq). Atuou como bolsista do Programa Institucional de Bolsa de Iniciação à Docência PIBID/CAPES. Ministrou aulas de Artes para os níveis fundamental e médio. Desenvolve fotográficos autorais e práticas de pesquisa com foco no ensino de fotografia explorando as possibilidades de produções imagéticas. Email:adriseferreira@hotmail.com

VAZQUEZ, Cecilia; MEDEIROS, Rosângela Fachel de; POZZI, Marion Divério Faria; SOUZA, Adrise Ferreira de. 9

Artes visuais e tecnologias na educação: história e contemporaneidade.

Revista GEARTE, Porto Alegre, v. 6, n. 1, p. 5-9, jan./abr. 2019.

Disponível em: http://seer.ufrgs.br/gearte 